\author{
Science journalism is under threat. What can scientists do to help?
}

W hat should any researcher expect from a journalist beyond the keen intelligence needed to see the newsworthiness of the researcher's work, and the ability to spell his or her name correctly?

For some scientists, the answer is probably 'Not much'. Many tend to think of science journalism as a kind of public-relations service, existing purely to explain new scientific findings to the masses. They may well enjoy reading the results, and give points for a writer's ability to convey the excitement of a discovery, but they will mainly judge an article on its scientific accuracy.

On top of this, some will see science journalism as an ally, useful for shaping the public's understanding of science-related issues such as nuclear proliferation, stem cells or genetically modified crops - and, not incidentally, for making the case for a thriving research enterprise to public and politicians alike.

And a minority, moving beyond perceived self-interest, will point to the deeper value of journalism, which is to cast a fair but sceptical eye over everything in the public sphere - science included. This kind of scrutiny is easy for researchers to applaud when a news report questions dodgy statistics, say, or dubious claims about uncertainties in evolution. It is not so easy when the story takes a critical look at sloppy animal-research practices, overblown claims about climate change or scientists' conflicts of interest. But such examinations are to the benefit of the enterprise as a whole: society needs to see science scrutinized as well as regurgitated if it is to give science its trust, and journalists are an essential part of that process.

At the moment, unfortunately, journalism's future is far from clear. At the 6th World Conference of Science Journalists, which will be held next week in London, and of which Nature is a sponsor, there will probably be many attendees wondering if this is journalism's swan song. Readers - and small ads, once a reliable earner — are migrating to the Internet. New business models in which papers are given away have caused damaging dislocations in some markets, as in Denmark.

This contraction is perhaps particularly bad news for journalists with specialist beats such as science - the kind of journalists who need an informed understanding of what they are writing about, and know which experts can provide context, and where appropriate criticism, of new results. But publishers tend to see that kind of expertise as a luxury when money is tight, especially when the same space can be easily filled with material from press releases and wire services.

Scientists can do little to stem this bloodletting. But whatever they can do to engage with those caught up in it, and ensure that questioning and informed science journalism persists, will be worthwhile. If there is to be a transition to new - perhaps philanthropic - business models for in-depth reporting or new types of analytical media, science journalism will integrate into them all the better if scientists are taking an active interest in its health. And if the future of the media truly is a dire landscape of top-100 lists, shouting heads and minimal attention span, then such efforts might at least defer the grim end.

Even amid the turmoil, however, scientists can help ensure that reporting about science continues to be both informed and accurate. They can start by recognizing that they will increasingly be talking to reporters who have no experience in science at all. A good start would be to have a look at the advice for academics speaking to journalists provided by Brad DeLong and Susan Rasky at the University of California, Berkeley (http://tinyurl.com/nljleo). Scientific societies, meanwhile, should redouble their efforts to help journalists working under a tight deadline find the experts they need to understand a subject.

Looking farther down the road, the scientific community should work with journalism schools and professional societies to ensure that journalism programmes include some grounding in what science is, and how the process of experiment, review and publication actually works.

Science and journalism are not alien cultures, for all that they can sometimes seem that way. They are built on the same foundation the belief that conclusions require evidence; that the evidence should be open to everyone; and that everything is subject to question. Both groups are comprised of professional sceptics. And whether it's directed towards an experiment or a breaking news story, each can appreciate the other's critical eye.

See also pages 1054, 1055, 1057 and 1061, and online at http://tinyurl.com/ sciencejournalism and http://tinyurl.com/natureforum.

\section{Raising the standards}

\section{A fledgling effort in China will show people what is happening on the environmental front.}

hina's central government has repeatedly declared its intention to clean up the environment, from the smoggy skies of Beijing

to the scummy green waters of Lake Tai in the Yangtze delta. However, ensuring that intentions are translated promptly, fairly and efficiently into action across the provinces is often a problem.

Two non-governmental organizations (NGOs) may be about to change this. On 3 June, the Institute of Public and Environmental Affairs (IPE) in Beijing and the Natural Resources Defense Council in New York posted their first Pollution Information Transparency Index on the Internet. The index ranks 113 Chinese cities on how well they informed the public about pollution-related legal violations in 2008 - specifically, by measuring their adherence to the national environment-information disclosure measures that came 